\title{
The culture and nature assets. The current crossovers and the agenda for the future
}

\author{
Arkadiusz Marciniak \\ Adam Mickiewicz University in Poznań, Poland
}

\begin{abstract}
The paper intends to provide an overview of major crossovers between cultural and natural heritage appearing and executing in political, administrative, economic, societal and academic domains. It discusses complicated processes that have led to overcoming a separation between these two largely distinct domains, which is strikingly embedded in western philosophy. The relevance of such crossovers is examined in the context of challenges imposed by the climate change and major shifts in the understanding of heritage and its role in the society. It concludes by providing some thoughts on the character of the future crossovers between cultural and natural heritage more effectively engaging with the contemporarily emergent issues of social significance.
\end{abstract}

Keywords: Natural Heritage, Cultural Heritage, Climate, Public Engagement, Sustainability

\section{Introduction}

The essay has two intertwined objectives. Firstly, it aims at presenting major forms of existing crossovers between cultural and natural heritage. They were developed as an explicit attempt to overcome the strongly embedded nature of separation between them as well as circumstances and practices leading to strengthening their disengagement. The relevance of such crossovers will be examined in the context of challenges imposed by the climate change that accelerated the hitherto developed forms of integration of natural and cultural heritage questioning their adequacy and demanding more efficient solutions and strategies be implemented at a great speed. These new challenges make it necessary to re-define the relevance and the character of nature and culture assets in drafting a new form of their integration. Climate change and the corresponding debate, questioning the hitherto dominant notion of heritage will be a point of departure for drafting an outline of the agenda for the future forms of integration of the culture and nature assets.

\section{Cultural and natural heritage divergences}

Heritage is the concept of a constructivist nature that comprises the development of democratic participation, with objectives to implement a 'shared responsibility' that involves citizens and society in the form of public action, to identify values, define priorities and manage heritage-led projects (Marciniak, Pawleta, Kajda 2018). In both natural and cultural heritage sectors, different factors are at play deciding on what is to be considered heritage and how that heritage may be used. The process of conceptualizing the cultural assets and 
the socially imposed obligations towards their protection remains largely homogenized.

Heritage has been commonly used for identity construction. It allows to highlight the peculiarities of a territory or human group, showing their characteristics and to build them into some symbols or social agents to promote social cohesion, identities and ideologies. Very often, heritage was mobilized to support particular state structures and political ideologies as well as legitimize the power structures. In this way, images, mythologies, artefacts, historical landscapes, etc. become resources for the present (Graham 2002).

The separation of culture and nature in Western ontologies led to the instrumentalization of the perception of natural and cultural worlds. It is deeply rooted in the past and has a wide range of consequences. In case of landscape, the nature-culture divide has narrowed down its scope to the technical management of either natural or cultural settings. Such binary separation of "natural" and "cultural" landscapes resulted in the formulation of separate national and international legislations and administrative procedures for each of them. This in turn led to the problematic separation of natural and cultural resources in the practice of planning and development. This also created the division between safeguarding natural heritage and cultural heritage. These processes were further strengthened and consolidated by legal regulations and administrative policies introduced and implemented by different authorities acting at different levels, be to local, national and international, setting up an agenda for either heritage management or nature conservation. As a results of these processes, cultural and natural heritage operate in two largely impenetrable organizational frameworks. Two different perspectives on landscape created a deep rift between the nature conservation specialising in natural and ,untouched" landscapes and culture protection focused on the cultivated landscape shaped by human activity.

Nearly every country in the world has laws and regulations to define and protect cultural assets. They are diverse in content and application, as they have evolved within their own national political and cultural contexts. Respective legislations vary in scope and have varied over time. In Scandinavia and Poland, for example, all archaeological materials are protected (owned) by the state from the moment of their discovery. By contrast, in England, archaeological material belongs to the landowner (with occasional exceptions of particular items of high monetary value, which can be claimed by the state on behalf of the monarch). In other countries, archaeological sites and materials are only protected if they are formally identified in the centrally organized registers.

Cultural heritage got inscribed a particularly significant role by the European Union. It defines Europe's cultural heritage as a common, inherited wealth, a legacy composed by knowledge and a valuable resource for economic growth, employment and social cohesion (Culture Heritage 2018). It developed effective tools to enhance these performances through treaties, financial programmes, awards and promotion activities. Even so the EU does not pay a major role in legislating for cultural heritage and cultural heritage management, it produced a number of policy treaties to establish the character of its different dimensions and relationship with other domains. The most important was the formulation of major principles relating to the cultural heritage in The Consolidated Treaty on the Functioning of the European Union itself (2012 Article 167). A similar purpose served both the European Convention on the Protection of the Archaeological Heritage (1992) and European Landscape Convention (2000).

Nature conservation regulations and practices have been shaped differently but share a 
number of common trajectories with that of culture. The first phase of institutionalizing the managerial practices related to natural heritage assets assumed an increase of their abundance. The concepts of rationing or sparsity were non-existent or a rarity at that time. The dynamic and speedy development resulted in a steady exhaustion of these resources. The speed of these degradative processes differed across different countries and types of targeted resources. One of the most appealing problems was pollution, in particular endangering the availability of drinkable water. Many other natural resources got lost to spoilage from pollution.

As people begin to become aware that their resources are becoming depleted, different strategies got implemented to counteract their loss. The early policies tend to be based on banning or limiting the exploitation of resources. For animals and plants this might involve the creation of special areas, such as parks or nature reserves, to protect some of the resources in pockets of the landscape. This had mainly some form of game management involving a system to manage animal resources so that they can be hunted in a controlled way. The corresponding solutions involved introducing different forms of restrictions on who can be hunt, permitting systems, or game reserves to breed animals for hunting. These initial efforts have contributed to the restriction in the loss of natural resources and, in some cases, have contributed to their regeneration. Consequently, many countries move on to the practice of nature conservation. The explicit plans for sustainable management and use of resources got formulated and implemented.

\section{Cultural and natural heritage crossovers}

Due to an increasing awareness of the depletion of natural resources, environmental movements strenghtened their political importance by framing the idea of threat, the need for care, and unpredictable forces. At the same time, cultural heritage was no longer seen as an important political player because of a misconceived image of an outmoded sector, saving artefacts merely for display in museums for future generations. Against politicised nature conservation, cultural heritage management became marginalised (Skoglund \& Svensson 2010). In these circumstances, the idea of cultural heritage as non-renewable resource was drafted and the way of thinking about heritage paved the ways to different groups of practitioners.

The call for integrative approach to natural and cultural assets involves a number of perspectives, as identified by Bell (2004). These comprise, among others, a historical perspective on biodiversity changes, in particular links between past extinctions and human activity such as gradual deforestation or drastic environmental change, deforestation causing social collapse, and warfare. As communities were clearly responsible for deforestation, one of the reasons for social collapse may have been the endemic environmental impact, the character of landscape acidification as a progressive process through the later Holocene, a result of both natural processes and human actions; an acceleration of acidification is due to the increased fossil fuel usage.

In the draft of the Territorial Agenda of the European Union 2020 (2011), adopted in 2011 by Ministers responsible for spatial planning and territorial development, both natural and cultural heritage are defined as parts of the EU's territorial capital and identity. The document stated that ecological values, environmental quality and cultural assets are crucial to well-being and economic prospects. Over-exploitation of these natural resources is recognized as a threat to territorial development. 
Despite these developments, integrative policies and solutions related to both cultural and natural heritage remain to be unsystematically defined and remain largely unknown by professionals from the corresponding sectors. This situation pertains despite continuing attempts by UNESCO and the Council of Europe to define different dimensions of the common ground, advocate the forms of cooperation by underlying the equilibrium between cultural heritage promotion, preservation and environmental sustainability.

However, promising crossovers between natural and cultural heritage remain to be addressed and executed in political, administrative, economic, societal and academic domains. These comprise policy making, administrative regulations, economic and sustainable developments, heritage conservation and protection agendas, public engagement solutions and the academic dispute.

One of the most visible and representative crossovers between natural and cultural domains is landscape. From the culture standpoint, landscape is a cultural property that represents the combined works of nature and the humans. According to UNESCO, different landscapes developed throughout the history, are illustrative of the evolution of human societies and their settlement over time, under the influence of the physical constraints and/or opportunities presented by their natural environment and of successive social, economic and cultural forces, both external and internal (Guidelines 2013). At the same time, natural landscape is defined as a landscape that has not been affected by human activity. It implies it is intact with all its elements to live and changes without any influences. The increasingly dominant understanding that all elements of the landscape are now under threat triggered the necessity to integrate efforts to restrict this danger. These comprise decreases in population, changes in agriculture, political interventions and climate change they all contribute to the challenge of maintaining shared heritage.

\section{Natural and cultural heritage crossovers in political and administrative domains}

The first institutional attempt to integrate natural and cultural sectors was made by UNESCO when adopted a landscape category in its World Heritage List (Cultural Landscapes 2019) It refers to the concept of mixed heritage, which is understood as containing elements of both natural and cultural significance.

In the framework of European legislation, natural and cultural heritage are combined in the unifying concept of landscape. The most prominent example of an integrated treaty within the framework of united natural and cultural ideals under the remit of landscape is European Landscape Convention (2000). The document sets out that landscapes are

"a basic component of the European natural and cultural heritage, contributing to human wellbeing and consolidation of the European identity" (Preamble of European Landscape Convention)

Accordingly, landscapes are to be safeguarded, but also to be used and enjoyed. Both European societies and governments have to balance these needs

A different dimension of these mutual relations was added by Council of Europe Framework Convention on the Value of Cultural Heritage for Society, known as the Faro Convention, adopted by the Council of Europe in 2005 (Council of Europe 2005). The document aims at promoting an integrated approach to policies concerning cultural, biological, geological and landscape 
diversity to achieve a balance between these elements. It also reinforces social cohesion by fostering a sense of shared responsibility towards the places in which people live.

The Florence Declaration on Heritage and Landscape as Human Values adopted by ICOMOS (The Florence Declaration 2014) defined landscape as a fusion of culture and nature, empowering a multidisciplinary approach towards cultural landscapes:

(a) cultural landscapes should not only be interpreted as conservation areas but also as places where sustainable development strategies can be successfully applied and

(b) concepts such as "natural" and "cultural" have lost much of their meaning, being replaced by a biocultural understanding, where not only settlements and agriculture, but also species and habitats are determined and preserved by people.

\section{Natural and cultural heritage crossovers in economy and sustainable development}

One of the most pronounced forms of integration between culture and environment is the concept of sustainable society and sustainable development. It is built on three pillars: social needs, economic activity, and the environment. The balance between these three elements is needed to achieve the effective sustainability. As landscape has both natural and cultural components, its new reformulation supposes a strong bond with sustainable human development. It can be a key point to stimulate economic activity, especially in places with important cultural and natural resources.

Hence, it is not surprising that the most eminent crossovers in cultural and natural assets of landscape are in the economic domain. Last years brought about severe threats in Europe and elsewhere influencing landscape. Large areas of land are being developed for new infrastructure projects or by spatial planning. Many countries have to cope with the direct effects of climate change. Some species and habitats can move or disappear because of global warming or disturbance by humans, and cultural heritage becomes endangered by rising sea levels or building activities.

These developments direct and indirect consequences in the economy. Since the 1990s a reflection on the economic potential of heritage - both cultural and natural - has generated evaluation policies and effective development strategies. Land use planning, pertaining to aspects of landscape and integrating heritage with regional policies, was developed as an element of sustainable development. It is explicitly stated by European Landscape Convention (2000) declaring that this approach

"concerned to achieve sustainable development based on a balanced and harmonious relationship between social needs, economic activity and the environment" (Preamble of European Landscape Convention)

One major challenge identified with sustainable landscape planning is uncertainty and unpredictability. Landscapes are always subject to change, so sustainable landscape planning needs to be adaptive. This adaptive planning requires transdisciplinary and monitoring (Ahern 2006). This involves an avoidance of land uses that deplete natural resources over a broad area and/or affect cultural heritage but at the same time retaining large contiguous or connected areas that contain critical habitats and/or elements of cultural importance. It is also required to minimise the introduction and spread of non-native species or implement 
land-use and land-management practices that are compatible with the natural potential of the area and/or the cultural heritage present in the area (Dale et al. 2000).

Due to interconnection of cultural and natural heritage, the adoption of integrated approaches aimed at protecting, managing and presenting the landscape might ease the implementation of more efficient planning strategies at the regional level. Among the sites that require integrated management of the natural and cultural assets are: rock art sites, which require complex management for heterogeneous nature of the artifact and integration into the environment; underwater cultural assets, which require strategies of search, retrieval and preservation completely environmentally friendly; or earthen theaters, requiring constant monitoring of the geological environment and the weather.

Different international organizations developed relevant policies and methodologies for operational activities of landscape management. They challenge the artificial separation between conservation and innovation, seeing cultural landscapes as lessons to be learnt in light of new models of economic development, responses to climate change, risk management, biodiversity conservation and the human well-being. The Economics of Ecosystems and Biodiversity (TEEB) - an international initiative advocating the benefits provided by biodiversity - carried out an analysis of the economic impact of biodiversity. It is clearly stated that

"The values of nature vary according to functional local bio-physical and ecological circumstances and the social, economic and cultural context. Intangible values, which may be reflected in society's willingness to pay to conserve particular species or landscapes, or to protect common resources, must be considered alongside more tangible values like food or timber to shops provide a complete economic picture" (Guidance 2013 11)

\section{Natural and cultural heritage crossovers in societal values}

The integration of environmental and cultural heritage has always been characterized by a condition of permeability and interrelation, as evidenced by the theories of social history and human geography. The Council of Europe interprets the concept of landscape as being the key element of individual and social wellbeing and that its protection, management and planning entail rights and responsibilities for everyone. In this regard, the public should have the right to co-create their landscapes via planning and management. This recognition can be further developed by combining articulations of existing environmental and cultural rights that adds new features to be considered, such as the right of active public involvement in decisions that influence landscapes (Egoz et al. 2011). The idea of the public having rights to landscapes touches upon the intangible values landscapes have within ongoing natural and cultural changes, which should allow for more opportunity to be involved in the policies governing landscapes.

The reorganisation of land to adapt to societal needs results often in rapid changes to the environment (Antrop 2006). The transformation of natural landscape into cultural landscape involves two types of processes:

(a) meaning assignment to a place and creation of rituals and cultural habits (to be considered as intangible heritage): for example, selected natural elements are considered sacred (trees, mountains, rivers, etc.) and

(b) creation of a physical structure aimed at the functional transformation of the 
place: for example thermal baths, theatres built in natural amphitheaters.

In order to make cultural and natural heritage available to the people, it should be systematically presented to different audiences. Integrated heritage can be characterised by approaches which take into account outreach 'by' and 'for' the public. By raising awareness and involving the public in heritage protection, sustainable landscape management can be accomplished. It is necessary to encourage people to care for their heritage, which should stand alongside the concept of sustainability in the context of landscape development.

The public outreach has different forms. Cultural and natural heritage are to be communicated in different ways, through enterprises, tourism and recreation. One of its common form is its opening up to public visitation, museums and art exhibitions. Integrated heritage also has the potential to be presented by private citizens. Information on the value of both natural and cultural heritage could be provided through tours or audio/visual technology, highlighting how they complement and sustain one another. Presenting heritage diversity is relevant for sustainable development.

A significant feature of the community engagement process for environmental heritage management is the close relationship - historically founded - between social history and territory. The knowledge of history of territories makes it possible to understand the profound relationship between environment and society, and to recognize the historic origin of land management methods.

Important approaches for cultural landscapes comprise the biography of landscape (e.g. Roymans et al. 2009) and the Historic Landscape Characterisation (HLC) (e.g. Aldred and Fairclough 2003). These approaches aim to deliver integrated information on historical landscapes in spatial planning by taking into account layered sources of information with a long term perspective. The biographical approach aims for an exploration of the long term and diverse histories of landscape by using a personal and social perspective. This exploration is based on two notions. Firstly, the idea that landscapes have the potential to absorb aspects of people's lives, works, and thoughts. Secondly, landscapes shape people own life-histories, temporalities and rhythms, surpassing human life. The HLC approach aims to characterise the distinctive historic dimension of today's urban and rural environment within a given area by mapping the comprehensive historic dimensions of landscape areas, focusing on locally distinctive components.

\section{Natural and cultural heritage crossovers in the academia}

The integrated approach to cultural and natural heritage has also numerous academic and conceptual iterations. Since the 1970s and 1980s, human-nature relations have been given due consideration in the research field of ecology and archaeology. As natural, untouched ecosystems are rare across the globe, archaeology is a key factor in the research of humanity's historical impact on living ecosystems (Bell 2004).

Environmental archaeology studies how the natural environment, resources and processes influenced past human behaviour, including long-term evolution and the adaption to the environment during the past thousands years. It aims to understand, by a multidisciplinary approach, whether the environment was a driving force for cultural change or mainly a factor in cultural developments. It involves studying paleoenvironmental remains to provide empirical evidence to show how humans have responded to environmental changes in the past. 
Bioarchaeology covers the study of all biological remains of humans, plants, animals and insects from archaeological sites. It is a singular disciplinary approach combining several layers of knowledge. It involves cooperation with botany, zoology, human osteology and funerary archaeology as well as geoarchaeology and isotope archaeology. The field encompasses, for example, investigations of ancient diets on the basis of stable isotope values in bone and teeth, and combines scientific methods with ecological, ethnographic and historical approaches to reconstruct past diet, land use and lifestyles in their evolutionary and social context.

Human ecology is the science that studies the interaction between humans, society and their environment (Richerson et al. 1996). It is interdisciplinary and therefore there need not be a division between scientists and human ecologists. It studies the relationship between humans and the biosphere over time and uses the insights of different disciplines, combining natural and social science. It can be studied at any scale and concerns different subjects of study, cultural characteristics, natural features or habitats. Historical ecology refers to the area in which human activity has taken place and explains the changes in the landscape based on records of human activities. As a resource, it uses archives as well as the landscape itself (Baleé 1998, Crumley 2014).

One of the main global challenges today is the establishment of sustainable society, meaning "development that meets the needs of the present without compromising the ability of future generations to meet their own needs" ( (United Nations Report 1987). 'Sustainable development' is therefore a unifying concept that needs an interdisciplinary approach involving collaboration from different unrelated academic disciplines in order to cross borders and create common goals, often with a social aim. Planning and public administration studies are the most suitable fields to investigate external integration within environmental developments, for which discourse analysis can be used for reflection on current practice. During that process, perception, interaction and communication are key themes for which an operation and its impact must be guided and controlled.

The complexity of landscape can be understood by being aware that landscape represents the relationship between people and place. After all, landscape is the setting for people's daily activities, where different environmental components - both natural and cultural - interact and are valued and appreciated by people. The outcome of all interactions create dynamic and evolving landscapes which can best understood in contextual and historical perspectives (Bohnet 2010). More recently, considerable research has emphasised the understanding of the archaeological-historical landscape with the purpose of integrating connected values within planning (Bloemers et al. 2010). However, the focus was mainly on integration of archaeology with disciplines belonging to the cultural heritage domain: historical geography and architectural history (Van der Valk 2010).

Although integrating data in archaeology has been common practice since the 1970s, it is mainly since the emergence of landscape studies that disciplines from different spectra of science are being combined. Landscape studies are therefore, by definition, interdisciplinary. Integration of the different disciplines needs to be bound by a common goal to create new knowledge and bring 'wholeness'. This holistic approach integrates different disciplines that can be deemed as 'useful'. This means that within the context of the landscape, these aim to bring together the 'whole' of the landscape. In this, the holistic approach differs from holistic ecology. The latter seems suggests that landscapes are to be considered a complex whole that is more than the sum of its parts, indicating that all elements in the spatial structure of the landscape are 
related to each other to form a complex system (Antrop 2006). A holistic approach, however, suggests that landscape development includes biological, physical and human components and is therefore a useful approach to challenge rapid change (Palang et al. 2000).

\section{Natural and cultural heritage crossovers: the case of climate change}

Natural heritage has been countlessly overexploited throughout the 20th century. They involved the conversion of large parts of the world's grasslands to arable fields, oil extraction or open pit mining exploitation have heavily changed ecosystems. Climate change is probably the most prominent environmental issue today.

Due to these dramatic changes of far reaching consequences, the conception of environment has significantly changed resulting in the revision of policies and methods of land management. This involved a shift from a conception focused on damage prevention to the formula based on the integration between man and its culture and environment, in compliance with the dynamic nature of global ecosystem. Climate change remains one of the most pronouncedly present issues in academic circles, public discourse, economic strategies and social discourse. This poses important challenges both for its scientific explanation and its humanistic understanding (Coen 2018). The most efficient mitigation strategy requires an improvement of cross-cultural and expert-lay dialogues and finding common ground for transdisciplinary collaboration aimed at integrating cultural and natural heritage domains. It makes it possible to go beyond the domain of climate researchers and make its meaningful beyond this narrow scholarly domain.

Rapid climate change makes also the existing strategies of protection and management of cultural assets largely unsatisfactory. It is due to the fact that it presents an array of challenges, such as from loss from erosion, fires and sea level rise to disconnection due to migration and loss of contact of affiliated communities, and damage deriving from conflict and other social changes. Climate change is certainly a whole-of-society problem, which means that heritage sector alone cannot solve its challenges.

Accordingly, the concept of co-dependency of humans on nature needs to be shifted to notions of sustainability in landscape research, policy, and management. This process of change was triggered by increasing public engagement with environmental issues such as spatial planning, pollution, overpopulation, recreation and tourism, as well as their effects on landscape resources.

\section{Beyond heritage. Nature and culture crossovers in the new era}

A reflexion of irrelevance and inaccuracy of the divide between cultural and natural heritage paced its way to different sectors of contemporary life. This is particularly pertinent if they are to meet challenges of the increasingly globalized world. This tendency has been additionally enhanced by recent theorizing these attempts, as manifested by the concept of connectivity ontologies, advocated by R. Harrison (2015), or multi-naturalist perspectives proposed by B. Latour (2011). Both authors aim to broaden the discussions of sustainability to encompass human and non-human actors and environments. The increasingly appealing call is also heard from the heritage sector. As cultural heritage encompasses elements of nature and nature is an intrinsic element of the past shared culture heritage, the need of integrating both types of heritage is inevitable. The preservation, management, and conservation of such integrated 
heritage should become an indispensable element of international and national policies as well as every conservation activity.

Existing crossovers convincingly proven a need to adopt a perspective based on a harmonic conception of the relationship between nature, human beings and global changes. The human attitude, in fact, adopted criteria and methodologies of systemic design, transforming the environment into a system of interconnections. As argued by Taylor (2009: 90) "systemsbased views, values, social structures, technologies and economic processes are rapidly emerging". These represent a paradigm shift in scientific and social thinking: from viewing the world as a collection of unconnected objects to seeing reality as a nested holarchy of interacting systems. Taylor (2009) then adds "[...] The emergence of this holistic worldview creates the potential for the rapid development of a sustainable societal system". A conception of ecosystem as "holism" moved then to a holistic concept of environment management, aimed at developing tools and policies for (ecological, social and economic) sustainability.

These attempts clearly correspond with the increasingly explicitly articulated voices calling for the redefinition of the concept of heritage as well as significance and relevance of both cultural and natural assets in the public domain. This requires to overcome the hitherto dominant pressure of neoliberal mandates in institutions to think in ways to make archaeology 'useful'. As convincingly argued by González-Ruibal et al. (2018), contemporary archaeology needs to formulate a new agenda accommodating three intertwined standpoints:

(a) Departure from the need for the heritagization of things, people and cultural processes and the largely elitist definition of the category of heritage,

(b) Involvement in a public debate by problematizing and challenging the ongoing debates and corresponding narratives, histories and identities. Its role should not be restricted to story-telling but be actively involved in historical explanation and position itself in relation to the contemporaneity and its most appealing issues,

(c) Pedagogical potential that converses with social movements, communities, and institution rather than teaches about the past.

When applied to the existing forms of combined forms of integration of cultural and natural heritage, this would require re-defining and modifying their hitherto developed formats. This is in particular to challenge and official position of the EC that used to consider that Europe's cultural heritage is a common, inherited wealth, a legacy composed by knowledge and a valuable resource for economic growth, employment and social cohesion. Hence, it made efforts to stimulate cultural heritage as a tool for social cohesion and integration, through regeneration of neglected areas, creation of locally-rooted jobs, and promotion of shared understanding and a sense of community.

A potential of the qualitatively new format of crossovers between the two domains is well illustrated by Bloemers at al. (2010), who outlined a new position of landscape in the changing world:

(a) Securing landscape as common good, and enhancing and safeguarding its key values to society,

(b) Coming to terms with mobility and evolving lifestyles, by better understanding changes in landscape perception and value brought about by different lifestyles, 
(c) Using landscape in its long-term social and human as well as physical transformations over many millennia to understand current processes of change,

(d) Using landscape as baseline and context for future changes, including - urgently to use knowledge of where society is starting from in terms of its long past interaction with the environment, in order to anticipate, model and plan for future change.

The future challenges for integrative approach to the culture and nature assets need to involve different way of encountering the materiality of both pasts, communicating them as well as using them the form of engagements of the contemporarily emergent issues of social significance. Such strategy will help landscape research to fulfil its potential for contributing to solving actual societal and environmental problems. The innovative edge of this vision is founded on the recognition of the mutual benefits that will flow when a strong humanistic, cultural and social perspective on landscape is combined with the physical and natural sciences approaches that more commonly form the focus of practical policy.

\section{References}

Ahern, J., 2006. Theories, methods and strategies for sustainable landscape planning, in: B. Tress, G. Fry \& G. Opdam (eds), From Landscape Research to Landscape Planning. Aspects of Integration, Education and Application. Dordrecht: Springer, 119-131.

Aldred, O., \& Fairclough, G., 2003. Historic Landscape Characterization. Taking Stock of the Method. London: English Heritage.

Antrop, M. 2006. Sustainable landscapes: contradiction, fiction or utopia?. Landscape and Urban Planning 75(3), 187-197.

BALÉE, W., 1998. Historical ecology: premises and postulates, in: W. BALÉE (ed.), Advances in Historical Ecology. New York: Columbia University Press, 13-29.

Beld, M., 2004. Archaeology and green issues, in: J. Bintliff (ed.), A Companion to Archaeology. Malden, Oxford, Victoria: Blackwell Publishing, 509-531.

Bloemers, T., Daniels, S., Fairclough, G., Petroli \& Stiles, R. (eds), 2010. Landscape in a Changing World; Bridging Divides, Integrating Disciplines, Serving Society. Strasbourg/Brussels: European Science Foundation ESF-COST.

Bohnet, I., 2010. The contribution of modelling and stakeholder engagement to transdisciplinary landscape research: an exploration of the Landscapes Toolkit, in: D.A. Swayne, Y. Wanhong, A.A. Voinov, A. Rizooli \& T. Filatova (eds), International Environmental Modelling and Software Society (iEMSs) 2010 International Congress on Environmental Modelling and Software Modelling for Environment's Sake. Ottawa: Fifth Biennial Meeting. http://www.iemss. org/iemss2010/index.php?n=Main.Proceedings.

Coen, D. 2018. Climate in Motion: Science, Empire, and the Problem of Scale. Chicago \& London: The University of Chicago Press.

Convention for the Protection of the Archaeological Heritage of Europe, 1992, Council of Europe. European Treaty Series No. 143. Accessed 27/11/2019

https://rm.coe.int/168007bd25

Council Of Europe Framework Convention On The Value Of Cultural Heritage For SOCIETY, 2005. Accessed 27/11/2019.

https://www.coe.int/en/web/conventions/full-list/-/conventions/treaty/199

CrumeY, C. 2014. What is historical ecology. Accessed 17/11/2019. 
http://www.hercules-landscapes.eu/blog.php?what_is_historical_ecology\&id=10

Cultural Landscapes, UNESCO 2019. Accessed 27/11/2019.

https://whc.unesco.org/en/culturallandscape/\#1.

Culture heritage in EU policies, 2018. Accessed 27/11/2019.

http: / / www.europarl.europa.eu/RegData/etudes/BRIE/2018/621876/EPRS_

BRI(2018)621876_EN.pdf.

Dale, V.H., Brown, S., Haeubner, R.A., Hobbs, N.T., Huntly, N., Naiman, R.J., Riebsame, W.E., Turner, M.G. \& VAlone, T.J., 2000. Ecological principles and guidelines for managing the use of land. Ecological Applications 10(3), 639-670.

Egoz, S., Makhzoumi, J. \& Pungetti, G. (eds), 2011. The Right to Landscape. Contesting Landscape and Human Rights. London: Ashgate.

European Landscape Convention. 2000, Council of Europe. European Treaty Series No. 176. Accessed 27/11/2019.

https://rm.coe.int/1680080621.

GonzÁlez-Ruibal, A., González, P.A. \& Criado-Boado, F., 2018. Against reactionary populism: towards a new public archaeology. Antiquity 92(362), 507-515.

GraHAM, B., 2002. Heritage as knowledge: capital or culture?. Urban Studies 39 (5-6), 1003-1017. Guidance Manual for the Country Studies, 2013. Accessed 27/11/2019.

http://www.teebweb.org/media/TEEB_GuidanceManual_2013_chapter-1.pdf.

GUIDELINES ON THE INSCRIPTION OF SPECIFIC TYPES OF PROPERTIES ON THE WORLD HERITAGE List. Annex 3, 2013. Accessed 27/11/2019. https://whc.unesco.org/archive/opguide05annex3-en.pdf.

HARrison, R., 2015. Beyond "natural” and "cultural” heritage. Toward an ontological politics of heritage in the age of Anthropocene. Heritage \& Society 8 (1), 24-42.

Latour, B., 2011. Politics of nature: East and West perspectives. Ethics \& Global Politics 4(1), $1-10$.

Marciniak, A., Pawleta, M. \& Kajda. K., (eds), 2018. Džiedzictwo we wspólczesnym świecie: kultura - natura - çlowiek. Kraków: Universitas.

Palang, H., Alumae, H., \& Mander, U., 2000. Holistic aspects in landscape development: a scenario approach. Landscape and Urban Planning (50), 85-94.

Richerson, P., Mulder, M.\& Vila, B., 1996. Principles of Human Ecology. Needham Heights: Simon \& Schuster.

http://www.thebreakthrough.org/images/Death_of_Environmentalism.pdf

Roymans, N., Gerritsen, F., Van Der Heijden, C., Bosma, K. \& Kolen, J., (eds), 2009. Landscape biography as research strategy. The case of the South Netherlands Project. Landscape Research 34(3), 337-359.

Skoglund, P. \& Svensson, E., (eds), 2010. Discourses of nature conservation and heritage management in the past, present and future. Discussing heritage and sustainable development from Swedish experiences. European Journal of Archaeology 13(3), 368-385.

TAYLOR, G.M., 2009. Systems thinking: The key to survival. 53rd Annual Conference of the International Society for the Systems Sciences 2009: Making Liveable, Sustainable Systems Unremarkable $1,90-115$.

Territorial Agenda of the European Union 2020, 2011. Accessed 27/11/2019.

https://ec.europa.eu/regional_policy/sources/policy/what/territorial-cohesion/ territorial_agenda_2020.pdf.

The Consolidated Treaty on the Functioning of the European Union, 2012. Accessed $27 / 11 / 2019$. 
https:/ / eur-lex.europa.eu/LexUriServ/LexUriServ.do?uri=CELEX:12012E/ TXT:EN:PDF.

The Florence Declaration on Heritage and Landscape as Human Values 2014. ICOMOS. 2014. Accessed 27/11/2019.

https://www.icomos.org/images/DOCUMENTS/Secretariat/2015/GA_2014_results/ GA2014_Symposium_FlorenceDeclaration_EN_final_20150318.pdf.

United Nations Report of the World Commission on Environment and Development. Our Common Future. 1987. Accessed 27/11/2019

https://www.are.admin.ch/are/en/home/sustainable-development/internationalcooperation/2030agenda/un-_-milestones-in-sustainable-development/1987--brundtlandreport.html.

Valk, van Der, A., 2010. Planning the past. Lessons to be learned from 'Protecting and Developing the Dutch Archaeological-Historical Landscape, in: T. Bloemers, H. Kars, A. van der VAlk \& M. Wijnen (eds), The Cultural Landscape and Heritage Paradox. Protection and Development of the Dutch Archaeological-Historical Landscape and its European Dimension. Amsterdam: Amsterdam University Press, 21-53. 
